\title{
Chorionic Sac
}

National Cancer Institute

\section{Source}

National Cancer Institute. Chorionic Sac. NCI Thesaurus. Code C34124.

The extraembryonic membranous sac surrounding the embryo of amniote vertebrates. 